\title{
Utilização do sítio sacrococcígeo na anestesia epidural em gatos domésticos
}

\section{Use of the sacrococcigeal space in the epidural anesthesia in domestic cats}

\author{
Jurandyr A. Câmara Filho, ${ }^{*}$ Luís Sérgio Ramadinha, ${ }^{\star \star}$ Mauro R. Rodrigues, ${ }^{\star * \star}$ Renato L.Silveira, ${ }^{\star \star \star \star *}$ Pedro A. Caldas ${ }^{\star \star \star \star *}$
}

\begin{abstract}
Resumo
A anestesia regional epidural é uma técnica anestésica muito utilizada, e valiosa, em determinados procedimentos em medicina veterinária. Gatos ainda são vistos por alguns como pequenos cães, em detrimento de inúmeras diferenças morfológicas, bioquímicas e fisiológicas, dentre outras, que exigem, cada vez mais, um maior grau de especialização dos profissionais que lidam com estas espécies. Este trabalho teve como objetivo investigar a viabilidade da utilização do espaço sacrococcígeo como sítio seguro de punção, para a confeç̧ão da anestesia epidural, em gatos domésticos, e comparar a utilização de dois diferentes calibres de agulha $(25 \times 7$ e $13 \times 4)$ nesta técnica. Utilizados 30 animais, com pesos variando entre 2 e $3 \mathrm{~kg}$, adultos, de ambos os sexos e considerados hígidos após exames clínicos e sem raça definida. Os animais receberam medicação pré-anestésica (xilazina, $1 \mathrm{mg} / \mathrm{kg}$, IM) sendo então procedida tricotomia e antissepsia da região coccígea. Introduzida a agulha no referido sítio até atingirmos o espaço epidural do assoalho do canal vertebral, administrava-se $9 \mathrm{mg} /$ $\mathrm{kg}$ de cloridrato de lidocaína no espaço epidural, sendo em seguida realizados os testes de avaliação da eficácia da anestesia regional. Foram realizadas radiografias simples para avaliar o posicionamento das agulhas após a punção e também radiografias contrastadas para observação dos limites da distribuição do contraste. Destarte, de acordo com os resultados obtidos, concluímos: a) que o espaço sacrococcígeo é factível para a utilização na técnica da anestesia epidural e clinicamente viável, por oferecer menor risco de lesão ao tecido nervoso da medula espinhal nestes animais; b) que a agulha calibre $13 \times 4$ foi a mais indicada para a punção devido à sua espessura e comprimento; e c) que o contraste, logo após a administração, difundiu-se até a altura de T10.
\end{abstract}

Palavras-chave: anestesia epidural; espaço sacrococcígeo; gato.

\begin{abstract}
The epidural regional anesthesia is a much valuable anesthetic technique used in determined procedure in veterinary medicine. Cats still are seen by some as small dogs in detriment of innumerable morphologic, biochemical and physiological differences, amongst others, that demand, each time more, a larger specialization degree of professionals, who deal with these species. This work had as its purpose to investigate the viability of using the sacrococcigeal space, as safe site of puncture for the epidural anesthesia confection in domestic cats and to compare the use of such differrent bores of needle $(25 \times 7$ and $13 \times 4)$ in this technique. It has been used 30 animals with weights between 2 and $3 \mathrm{~kg}$, adults, of both Sex, considered healthy after clinical examinations and without definite race. The animals had received pre- anesthetic medication (xilazine, $1 \mathrm{mg} / \mathrm{kg}, \mathrm{IM}$ ) being, then, proceeded tricotomia and antesepsis from the coccigeal region. Introduced the needle in the related site until reaching the epidural space floor of vertebral channel, $9 \mathrm{mg} / \mathrm{kg}$ of clorhidrate of lidocaine was managed in epidural space, being after that, carried through evaluation tests to observe the regional anesthesia effectiveness. Simple $x$-rays had been carried through to evaluate the thread of the needles after puncture, and also $x$-rays contrasted for comment of the distribution limits of contrast. Thereby, in accordance with the obtained results, we conclude that the sacrococcigeal space is feasible for the use in epidural technique and clinically viable for offering minor risk of injury to nervous tissue of the spinal cord in these animals. The needle bore $13 \times 4$ was indicated for puncture, due to its thickness. Size and that the contrast, soon after the management, spread out the height of T10.
\end{abstract}

Keywords: epidural anesthesia; sacrococcigeal space; cat.

\footnotetext{
*Universidade Federal Fluminense, Rua Professor Hernani de Mello n. 101 Niterói, RJ, Brasil. jurabreu@bol.com.br

**Universidade Federal Rural do Rio de Janeiro, Km 47, Seropédica, RJ, Brasil.

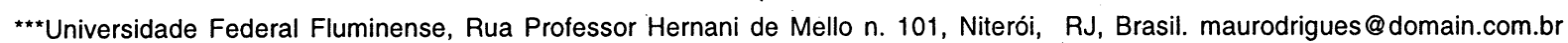

${ }^{\star \star \star \star *}$ Universidade Federal Fluminense, Rua Professor Hernani de Mello n. 101 Niterói, RJ, Brasil. HYPERLINK "mailto:silveira@web4u.com.br" silveira@web4u.com.br

$\star \star \star \star \star$ Clínica veterinária Bom Pastor, São Gonçalo-RJ
} 


\section{Introdução}

As anestesias regionais são procedimentos muito utilizados na clínica médica e cirúrgica de pequenos animais. Suas aplicações possuem vantagens e desvantagens que devem ser consideradas quando da escolha da conduta anestésica a ser adotada. As anestesias espinhais podem ser de dois tipos: a intratecal (subaracnóide) e a epidural (peridural). A segunda parece ter vantagens em relação à primeira no que tange à segurança da técnica, embora os efeitos de ambas sejam os mesmos (Massone, 1988).

A anestesia epidural é de baixo custo, fácil aplicação (desde que o profissional esteja treinado) e de grande valia nos pacientes cuja utilização da anestesia geral esteja, de alguma maneira, contra-indicada. A sua aplicação e a compreensão dos efeitos requerem conhecimentos anatômicos. Teoricamente, pode-se aplicar a solução anestésica no espaço epidural em qualquer ponto do canal vertebral, tendo em vista que este espaço existe ao longo de toda a coluna, onde houver duramáter. Utilizam-se sítios caudais ao cone medular, o que torna a técnica de aplicação mais segura evitando-se, assim, lesões à medula espinhal (Nicholas \& Leslie, 1992; Hilbery, 1992).

O local de aplicação do anestésico varia conforme a espécie animal, de acordo com o local de término da medula espinhal. Em cães, o cone medular (limite caudal da medula espinhal) situa-se entre L6 e L7, e, por conseguinte, o sítio para a anestesia epidural é o espaço lombossacro, o que também é recomendado, pela maioria dos autores, para os gatos (Handerson, 1977; Bhon,1981).

Nos gatos domésticos, o cone medular atinge o espaço da primeira vértebra sacral (Câmara Filho et al., 1998) ( Figura 1).

Este trabalho teve como objetivo avaliar a viabilidade da utilização do espaço sacrococcígeo como sítio de punção para a prática da anestesia epidural em gatos domésticos, comparar dois diferentes calibres de agulhas e observar a distribuição regional do contraste iodado no espaço epidural após a administração deste no sítio preconizado.

\section{Material e métodos}

Utilizaram-se 30 animais adultos, pesando entre 2 e $3 \mathrm{~kg}$, sem raça definida, clinicamente hígidos, machos e fêmeas.

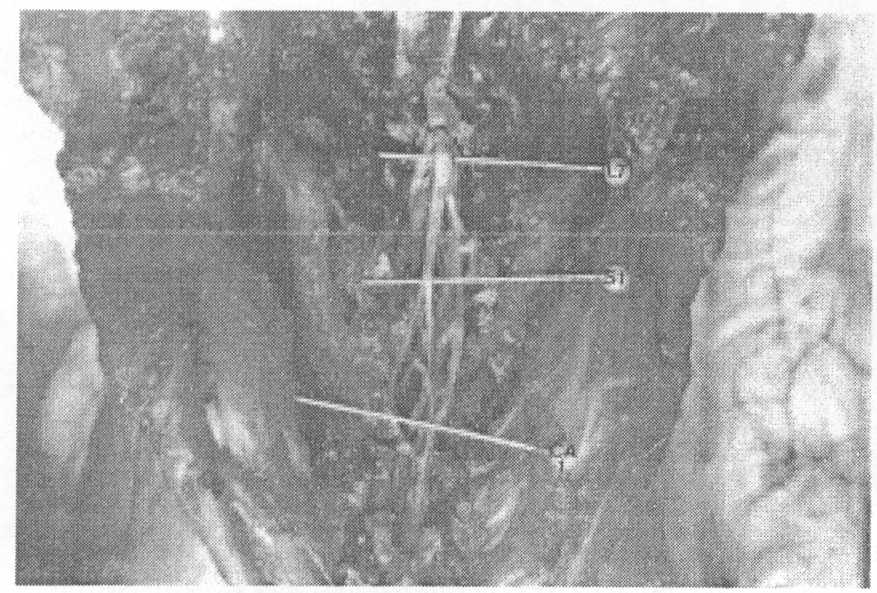

Figura 1: Cone medular terminando no espaço da $1^{\mathrm{a}}$ vértebra sacral. Vista dorsal
Provenientes do Centro de Zoonoses Paulo Dacorso Filho (Niterói, RJ), e da Clínica Veterinária Bom Pastor, São Gonçalo-RJ. Os procedimentos experimentais foram realizados no Hospital Veterinário do Instituto de Veterinária da Universidade Federal Rural do Rio de Janeiro e na Clínica Bom Pastor.

Todos os animais foram submetidos a exame clínico neurológico, tais como teste do reflexo patelar e nociceptivo, antes e depois da realização da técnica anestésica.

Após o jejum de 12 horas, os animais foram farmacologicamente contidos com cloridrato de xilazina ${ }^{1}$ na dose de 1 $\mathrm{mg} / \mathrm{kg} / \mathrm{IM}$, após o que, procedia-se a tricotomia na região sacrococcígea; procedia-se a antissepsia com solução iodada ${ }^{2}$ sobre a pele desta região.

Em cinco animais, escolhidos aleatoriamente, foram realizadas radiografias simples, após a introdução de agulhas $13 \times 4$ e $27 \times 8$, no espaço sacrococcígeo, para verificar a viabilidade das agulhas e do espaço para realização do procedimento anestesiológico (Figuras 2 e 3). Em cinco animais, também escolhidos aleatoriamente, realizamos epidurogramas, puncionando o espaço sacrococcígeo com agulha $13 \times 4$, utilizando como meio de contraste o lohexol, ${ }^{3}$ com a mesma quantidade de anestésico que seria utilizado para realização da anestesia, para verificar a que nível o contraste se difundiria pelo canal vertebral, tentando estabelecer uma correlação entre a difusão do contraste e a do anestésico (Figura 4).

Após dois a três minutos de administração do contraste realizavam-se radiografias em posição lateral, com aparelho de raios $X^{4}$ com potência de $70 \mathrm{kv}$ e $25 \mathrm{~mA}$; utilizando-se filmes radiográficos de tamanho $18 \times 24$, com chassis correspondentes providos de écran intensificador universal. Os procedimentos radiográficos de revelação, fixação e lavagem das películas obedeceram à técnica de rotina, com método manual.

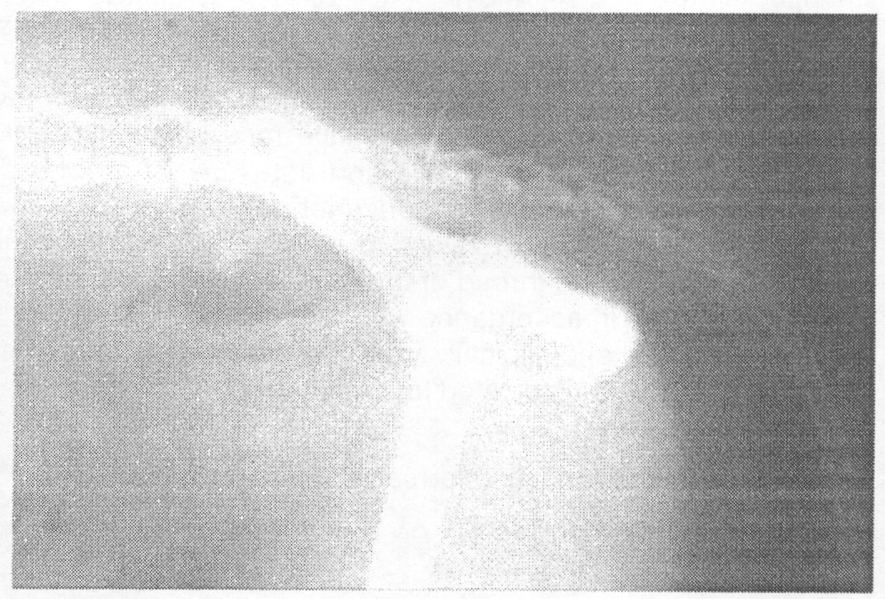

Figura 2: Radiografia simples com agulha $13 \times 4$ introduzida no espaço sacrococcígeo. Vista radiográfica lateral

\footnotetext{
Rompum (Laboratório Bayer).

2 Polvidine Tintura Ceras Jhonson).

${ }^{3}$ Omnipaque (winthrop S.A) ${ }^{4}$ Aparelho GE norte-americano fabricado em Chicago, filme da marca
Kodak.
} 


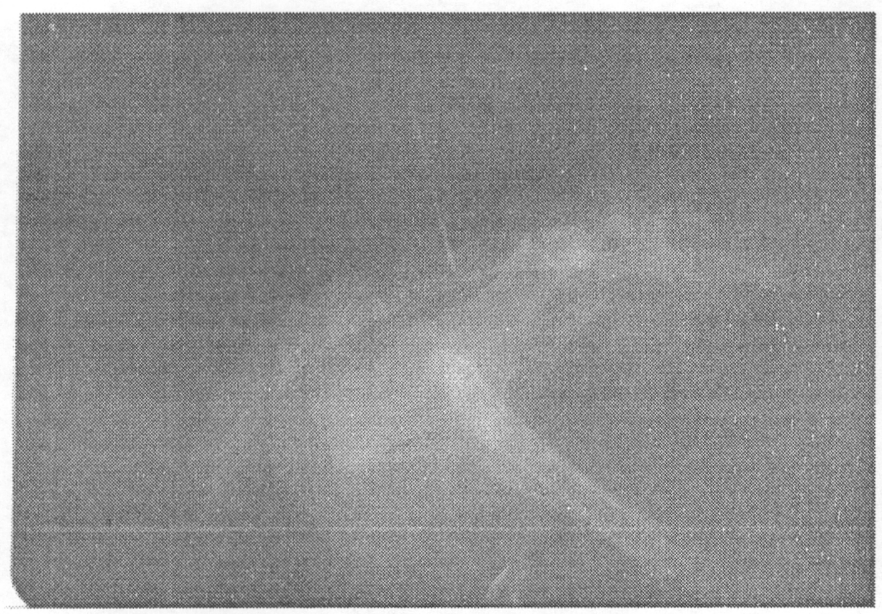

Figura 3: Radiografia simples com agulha $27 \times 8$ introduzida no espaço sacrococcígeo. Vista radiográfica lateral
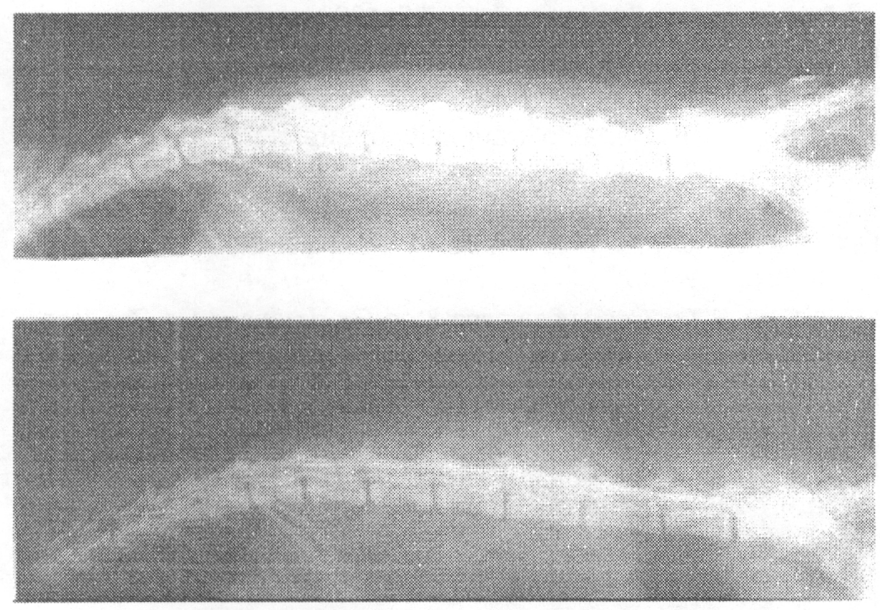

Figura 4: Epidurograma realizado após a introdução do contraste no espaço sacrococcígeo, visualizando-se o contraste na $10^{\mathrm{a}}$ vértebra torácica. Vista radiográfica Lateral

Em 20 animais, submetidos à pré-anestesia, realizou-se 0 teste do reflexo patelar e teste do reflexo nociceptivo (beliscamento das regiões abdominal e lombar). Após os testes, realizou-se a técnica de anestesia epidural para gatos descrita por Lumb e Jones (1979) com algumas modificações; posicionou-se o animal em decúbito ventral, com o dedo polegar e o dedo anular identificaram-se as duas tuberosidades ilíacas, e com o dedo indicador a fossa lombossacra na linha média dorsal; em seguida, identificaram-se os processos espinhosos da primeira, segunda e terceira vértebras sacrais caudais à fossa lombossacra, para se localizar o espaço sacrococcígeo logo após a terceira vértebra sacral.

Em seguida, introduziu-se uma agulha no espaço sacrococcígeo na posição vertical até atingir o espaço epidural, injetando-se lentamente $9 \mathrm{mg} / \mathrm{kg}$ lidocaína ${ }^{5} 2 \%$ sem vasodilatador, após realização de pressão negativa na seringa através do êmbolo para assegurar-se de que a agulha não fosse introduzida por via intravascular. Normalmente observava-se movimento de cauda, seguido de relaxamento.

${ }^{5}$ Cloridrato de Lidocína (Apsen).
Os reflexo patelar e cutâneo foram testados para constatar a perda da sensibilidade das regiões citadas anteriormente.

\section{Resultados}

Para punção do espaço sacrococcígeo para procedimentos radiograficos e anetesiológicos, as agulhas $13 \times 4$ e $27 \times 8$ apresentaram ser satisfatórias. Após análise das radiografias simples e realização do procedimento, observou-se que a aguIha $13 \times 4$ foi aparentemente melhor, pois possui menor espessura e comprimento, penetrou no espaço epidural com facilidade (Figuras 2 e 3 ).

Nos epidurogramas, após dois a três minutos de administração do meio de contraste, utilizando agulha $13 \times 4$, constatamos a presença do mesmo, no canal vertebral, desde a $10^{\text {a }}$ vértebra torácica até as vértebras coccígeas (Figura 4).

Nos exames neurológicos após a pré-anestesia, verificou-se presença de sensibilidade nas regiões abdominal e lombar, no teste nociceptivo e reflexo patelar positivo. Estes reflexos foram perdidos logo depois da anestesia epidural no sítio preconizado.

\section{Discussão}

Uma das técnicas de anestesia regional, muito utilizada em medicina veterinária é a anestesia epidural. Ela é escolhida sempre que haja contra-indicação da anestesia geral, por qualquer motivo. A técnica de confecção desta anestesia regional é preconizada por vários autores, pela utilização do sítio lombossacro (tanto no cão como no gato), para a introdução da agulha, visando a transfixação dos planos anatômicos necessários para se atingir o assoalho do canal vertebral, e injetar a solução anestésica no espaço epidural (Handerson, 1997; Bohn, 1981; Cruz, 1992; Kennedy, 1976).

Entretanto, a utilização da mesma técnica, puncionando o sítio lombossacro, indistintamente para cães e gatos, pode gerar casos de perda de sensibilidade em regiões cutâneas abdominais, dos membros posteriores e cauda, ou, até mesmo, paralisias, o que não é desejável em nenhuma técnica, pois são complicações pós-anestésicas indesejáveis. O sítio lombossacral de punção nesta técnica anestésica não é segura para os gatos, tendo em vista que a medula espinhal desses animais avança até pontos além de L6 e L7 (Câmara Filho, Rodrigues e Silveira, 1998 ).

Outros autores (Klide e Soma, 1968; Mckelvey e Hollingshed, 1994) defendem a tese de que a medula espinhal e o. saco dural, do gato doméstico, estendem-se até uma vértebra a mais que no cão, tornando a técnica anestesiológica mais perigosa.

A punção do espaço epidural para realização da anestesia epidural pode ser realizado em qualquer espaço intervertebral, tendo em vista que é uma cavidade entre a dura-máter e o periósteo do canal vertebral, e estende-se do forame magno até a 4를 vértebra coccígea; no entanto, utilizam-se sítios posteriores, tornando a técnica mais segura (Hall e Clark, 1987).

O presente experimento utilizou o sítio sacrococcígeo para realização da técnica de anestesia epidural. Para isso, foram realizadas radiografias simples e contrastada, demonstrando que este espaço é viável como técnica e seguro para o paciente para ser puncionado, de acordo com os resultados de Hall e Clark (1987). 
Assim, torna-se pouco prudente a utilização do sítio lombossacro para esta técnica anestésica, em desacordo com as afirmações de Handerson, 1997; Bohn, 1981; Cruz, 1992; Kennedy 1976.

Klide e Soma (1868) utilizam para punção do espaço lombossacro em gatos agulha de tuohy de calibre $17 \times 7.6$. Porém, como demostrado neste estudo, o uso de agulha 13 $x 4$ foi eficiente e mostrou-se de boa norma para a realização desta anestesia em animais adultos desta espécie.

Hall (1970) afirma que são utilizados vários tipos de drogas anestésicas para a prática de anestesia epidural em gatos; utilizamos xilocaína a $2 \%$, sem vasodilatador, na dosagem de $9 \mathrm{mg} / \mathrm{kg}$, obtendo analgesia da região abdominal e dos membros posteriores, de boa qualidade, comprovada com testes neurológicos tais como o reflexo patelar e nociceptivo.

\section{Referências bibliográficas}

BOHN, F. K. Device for positioning small animals during anaesthesia. Laboratory Animals, v. 15, n. 3, p. 289, 1981.

CRUZ, J. I. New Developments in veterinary epidural anaesthesia. Veterinary-Annual, n. 32, p. 165-173, 1992

CÂMARA FILHO, J.A.; RODRIGUES, M., SILVEIRA, R. Determinação morfológica do cone medular espinhal no espaço da primeira vértebra sacral. Revista do Centro de Ciências Médicas da UFF. v. 2, n. 2, p. 55- 59, abril 1998.

HANDERSON, R. A. Epidural anaesthesia in small animals. Auburn Veterinarian. v. 34, n. 1, p. 20-35, 1977.

HALL, L. W. Anestesia y analgesia veterinaria. 2.ed. Zaragoza. Acribia. 1970. p.123-127.

CLARKE, K. W. Anestesia veterinária. 8. ed. São Paulo: Manole, 451 p. p. 208-215. 1987.

\section{Conclusões}

De acordo com os resultados obtidos, concluímos que:

1 O espaço sacrococcígeo pode ser utilizado para realização de anestesia epidural nos gatos domésticos.

2 A agulha ideal para este procedimento parece ser a $13 \times 4$, pois sua espessura e comprimento facilitaram a confecção da mesma.

3 A dose de $9 \mathrm{mg} / \mathrm{kg}$ de lidocaína a $2 \%$ sem vasodilatador demonstrou ser suficiente para o procedimento anestesiológico.

4 A utilização do espaço sacrococcígeo é o mais indicado nos procedimentos invasivos radiográficos e aneste-siológicos da medula espinhal, para os gatos domésticos, e não o espaço lombossacro, postulado por diversos autores.

HILBERY, A. D. R. Manual de anestesia de los pequeños animales. Zaragosa: Acribia. Cap. 8. p. 72-75. 1992.

KLIDE, A. M.; SOMA, L.R. Epidural analgesia in the dog and cat. J.A.V.M.A., 1968. p. 153-173.

KENNEDY, R. K. Repair of traumatic rupture of the urinary bladder using epidural analgesia in a cat. Feline Practice. v. 6, n. 6, p. 1617, 20, 1976.

LUMB, W. V., JONES, W. E. Anestesia veterinaria. México: Continental, 1979. p. 429-433.

MASSONE, F. Anestesia veterinária. 8. ed. Rio de janeiro: Ed. Guanabara Koogan. 1988. p. 44-49.

MCKELVEY, D., HOLLINGSHEAD, W. K., Small animal anesthesia. Ed. Mosby. Cap. 7, 1994. p. 290-294.

NICHOLAS, H. LESLIE, M. E., Farmacologia e terapêutica em veterinária. 6. ed. Rio de Janeiro: Ed. Guanabara Koogan. 1992. p. 337-345. 